\title{
Precise Synthesis and Thin Film Self-Assembly of PLLA- $b$-PS Bottlebrush Block Copolymers
}

\author{
Eunkyung Ji ${ }^{\dagger}$, Cian Cummins ${ }^{\dagger}(\mathbb{D})$ and Guillaume Fleury * \\ Laboratoire de Chimie des Polymères Organiques, Université de Bordeaux, CNRS, Bordeaux INP, LCPO, \\ UMR 5629, F-33600 Pessac, France; eunkyungji@gmail.com (E.J.); c.cummins1988@gmail.com (C.C.) \\ * Correspondence: Guillaume.Fleury@enscbp.fr \\ + These authors contributed equally to the manuscript.
}

Citation: Ji, E.; Cummins, C.; Fleury, G. Precise Synthesis and Thin Film Self-Assembly of PLLA- $b$-PS Bottlebrush Block Copolymers. Molecules 2021, 26, 1412. https:// doi.org/10.3390/molecules26051412

Academic Editor: Irrea Alessia

Received: 16 February 2021

Accepted: 3 March 2021

Published: 5 March 2021

Publisher's Note: MDPI stays neutral with regard to jurisdictional claims in published maps and institutional affiliations.

Copyright: (c) 2021 by the authors. Licensee MDPI, Basel, Switzerland. This article is an open access article distributed under the terms and conditions of the Creative Commons Attribution (CC BY) license (https:/ / creativecommons.org/licenses/by/ $4.0 /)$.

\begin{abstract}
The ability of bottlebrush block copolymers (BBCPs) to self-assemble into ordered large periodic structures could greatly expand the scope of photonic and membrane technologies. In this paper, we describe a two-step synthesis of poly(L-lactide)- $b$-polystyrene (PLLA- $b$-PS) BBCPs and their rapid thin-film self-assembly. PLLA chains were grown from exo-5-norbornene-2-methanol via ringopening polymerization (ROP) of L-lactide to produce norbornene-terminated PLLA. Norboneneterminated PS was prepared using anionic polymerization followed by a termination reaction with exo-5-norbornene-2-carbonyl chloride. PLLA- $b$-PS BBCPs were prepared from these two norbornenyl macromonomers by a one-pot sequential ring opening metathesis polymerization (ROMP). PLLA$b$-PS BBCPs thin-films exhibited cylindrical and lamellar morphologies depending on the relative block volume fractions, with domain sizes of $46-58 \mathrm{~nm}$ and periodicities of 70-102 nm. Additionally, nanoporous templates were produced by the selective etching of PLLA blocks from ordered structures. The findings described in this work provide further insight into the controlled synthesis of BBCPs leading to various possible morphologies for applications requiring large periodicities. Moreover, the rapid thin film patterning strategy demonstrated ( $>5 \mathrm{~min}$ ) highlights the advantages of using PLLA$b$-PS BBCP materials beyond their linear $\mathrm{BCP}$ analogues in terms of both dimensions achievable and reduced processing time.
\end{abstract}

Keywords: bottlebrush block copolymer; sequential ROMP; thin film self-assembly; nanoporous templates

\section{Introduction}

Bottlebrush block copolymers (BBCPs) are densely grafted polymers with two or more different polymeric side chains attached to a linear polymeric backbone. The densely grafted side chains of BBCPs yield to an extended backbone conformation and thus reduce chain entanglement, which lowers kinetic barriers for self-assembly. Accordingly, BBCP systems undergo a rapid microphase separation for nanostructures exhibiting large periodicities beyond $100 \mathrm{~nm}$. Due to these unique assets, BBCPs have received tremendous attention for photonic, surface coating, and drug delivery applications [1-10]. BBCPs are prepared either by grafting from, grafting to, or grafting through approaches $[6,11,12]$. Among these approaches, the grafting through method leverages the robust control of the macromolecular parameters, i.e., side chain length, backbone degree of polymerization, and grafting density. This route can afford 100\% grafting density (one side chain per backbone repeating unit) using macromonomers (MMs) synthesized prior to the backbone polymerization. However, this route also suffers from the high viscosity of the reaction media and the steric hindrance linked to the bulky MMs [1,6].

To address these problems, ring opening metathesis polymerization (ROMP) of norbornenyl MMs can be used by taking advantage of both the release of ring strain energy from cyclic olefins upon ring opening, and the use of highly active ruthenium-based catalysts. 
Rajaram et al. demonstrated the polymerization of sterically hindered dendronized norbornenes using the highly active, fast-initiating third-generation Grubbs catalyst (G3) [13]. Subsequently, in 2009, Xia et al. reported the use of G3 for ROMP of MMs, producing various brush polymers with high molecular weights and a narrow dispersity [14]. They also demonstrated for the first time the polymerization of high molecular weight, narrowly dispersed brush block- and random- copolymers via sequential ROMP of MMs based on poly(n-butyl acrylate) (PnBA), poly(t-butyl acrylate) (PtBA), polystyrene (PS), and polylactide (PLA) [1].

Over the past decade, researchers have reported different synthetic routes to synthesize BBCPs via ROMP of norbornenyl MMs, and their self-assembly into ordered nanostructures with large domain sizes; however, only a few studies investigated $\mathrm{BBCP}$ morphological transitions depending on the volume fraction of the two blocks. Given the complex architecture of BBCPs, backbone and side chain lengths as well as block volume fractions need to be considered to establish a phase diagram as recently described by Zhulina et al. [15]. Runge et al. demonstrated how coil BBCPs could produce large cylindrical domains (100-200 nm), and the backbone chain length controlled domain sizes [16]. Subsequently, they reported the lamellar, cylindrical, or spherical morphologies depending on the BBCP chemical compositions [17]. Nevertheless, BBCP self-assembly produces lamellar morphologies over a large window of the complex phase diagram due to a highly extended backbone conformation [1,15,18-21].

To obtain non-lamellar morphologies, Jiang et al. introduced gradient interfaces between two blocks (PS and PLA): from PS-rich, followed by a gradated transition from PS to PLA, to PLA-rich along the backbone [22]. Side-chain symmetric gradient BBCPs exhibited cylindrical morphologies while their BBCP analogs arranged into lamellae. Additional efforts have been made to tune the $\mathrm{BBCP}$ morphologies by manipulating backbone or side chain asymmetry. For example, Gai et al. reported cylindrical morphologies from PS-b-PEO BBCPs at a high volume fraction of PEO $\left(f_{\mathrm{PEO}} \sim 0.8\right)$ [23]. Cho et al. demonstrated how asymmetric PS-stat-PLA bottlebrush statistical copolymers with longer PLA ( $5.6 \mathrm{kDa})$ and shorter PS (2.0 kDa) side chains exhibited cylindrical (at $f_{\mathrm{PS}}=0.41-0.50$ ) and lamellar (at $\left.f_{\mathrm{PS}}=0.67-0.70\right)$ morphologies [24]. Besides, lengthy annealing treatments are commonly employed for the promotion of the self-assembly in thin films [19]. To our knowledge, the best reported BBCP thin film study required $2-4 \mathrm{~h}$ of solvent annealing of a PS- $b$-PLA BBCP to produce well-ordered lamellar patterns [25]. Due to the complex interplay between architecture of BBCPs and self-assembly behavior in thin film, additional studies on microphase separated BBCPs are required to manipulate as well as understand $\mathrm{BBCP}$ thin film processing.

In this article, we report a route to synthesize BBCPs containing PLLA and PS, and detail their rapid self-assembly and morphological transitions depending on the PLLA block volume fraction using solvent vapor annealing. PLLA was chosen as one of polymeric side chains in our attempts to obtain various nanostructures taking advantage of the semi-crystallinity of PLLA [26-28]. In addition, selective etching of the PLLA block can create porous thin films, which can be used as sacrificial templates in the field of nanotechnology [29,30]. BBCPs were prepared by a two-step synthesis: (1) formation of MMs via anionic polymerization of styrene and ring opening polymerization of L-lactide using norbornene derivatives as an initiator and end-capping agents, respectively, and (2) sequential ROMP of the two MMs. PLLA volume fractions were controlled by adjusting the feed ratios between PLLA and PS MMs. PLLA- $b$-PS BBCP thin-films were then developed showing an impressive capacity to self-assemble with periods as large as $102 \mathrm{~nm}$ in the lamellar system described. Lastly, the BBCP thin-films were treated with oxygen plasma etching to form nanoporous templates.

\section{Results and Discussion}

\subsection{Synthesis of Macromonomers}

The desired norbornene-terminated MMs were prepared by a one-pot polymerization using norbornene derivatives as an initiator or an end-capping agent (see Scheme 1). Nor- 
bornenyl PLLA MM (NB-PLLA) was obtained by ring opening polymerization of L-lactide using exo-5-norbornene-2-methanol as an initiator. Norbornenyl PS MM (NB-PS) was synthesized by previously reported procedures: anionic polymerization of styrene, followed by reacting with ethylene oxide and then exo-5-norbornene-2-carbonyl chloride [31]. In particular, exo-norbornenes were used in this study because of their significantly higher reactivity than endo-isomers, arising from steric interactions between growing polymer chains and incoming monomers [14,32]. Molecular characteristics of these two MMs obtained by SEC, NMR, and MALDI-TOF MS are summarized in Table 1.

(oluene

NB-PLLA
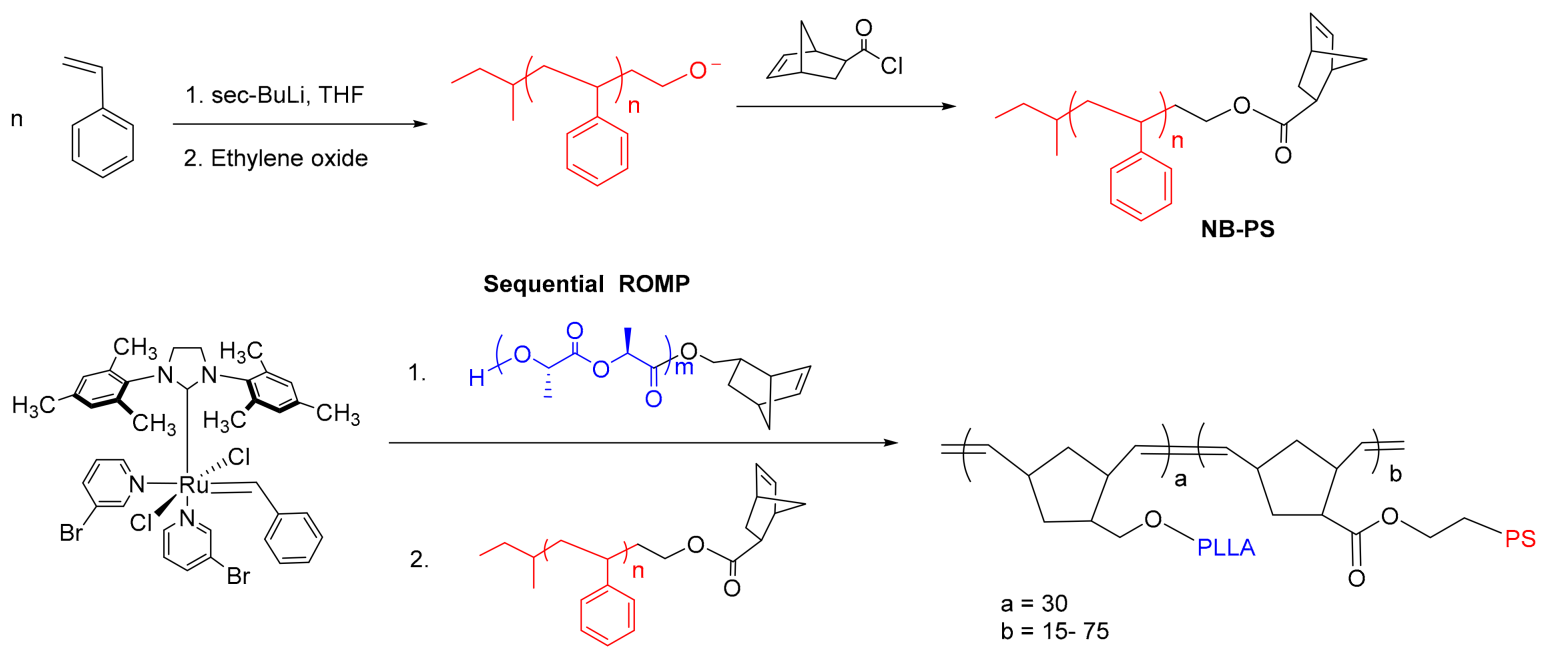

Scheme 1. Synthetic scheme for the preparation of norbornene-functionalized MMs and sequential ROMP of MMs.

Table 1. Molecular characteristics of NB-PLLA and NB-PS MMs.

\begin{tabular}{|c|c|c|c|c|c|c|}
\hline & $\begin{array}{c}M_{n, \mathrm{SEC}} \\
(\mathrm{Da})^{\mathrm{a}}\end{array}$ & $\bigoplus^{a}$ & $\begin{array}{c}M_{n, \mathrm{NMR}} \\
\text { (Da) }^{\mathrm{b}}\end{array}$ & $\mathrm{DP}_{\mathrm{NMR}}{ }^{b}$ & $\begin{array}{l}M_{n, \mathrm{MALDI}} \\
\quad \text { (Da) }^{\mathrm{c}}\end{array}$ & $\bigoplus^{c}$ \\
\hline NB-PLLA 2.58 & 2580 & 1.08 & 1850 & 12 & - & - \\
\hline NB-PLLA $3.68 \mathrm{k}$ & 3680 & 1.16 & 2570 & 17 & 2660 & 1.05 \\
\hline NB-PS ${ }_{3.28 k}$ & 3280 & 1.40 & 3450 & 31 & 3260 & 1.10 \\
\hline
\end{tabular}

${ }^{a}$ Determined by SEC in THF using refractive index detector with PS standards. ${ }^{b}$ Calculated by comparing integrations of PS and PLLA proton signals from ${ }^{1} \mathrm{H}$ NMR spectra in $\mathrm{CD}_{2} \mathrm{Cl}_{2} \cdot{ }^{c}$ Determined by MALDI-TOF MS (linear mode).

NMR spectroscopy confirms the complete attachment of norbornene end groups to PLLA and PS chains (Figures S1 and S2). In the ${ }^{1} \mathrm{H}$ NMR spectra, the norbornenyl olefinic protons were observed at $\delta 6.08 \mathrm{ppm}$ (NB-PLLA) and $6.02 \mathrm{ppm}$ (NB-PS). ${ }^{13} \mathrm{C}$ NMR spectra also exhibit two peaks at $\delta 136$ and $137 \mathrm{ppm}$ (NB-PLLA) and $\delta 136$ and $138 \mathrm{ppm}$ (NB-PS), which are attributed to the double bonds of norbornene. Furthermore, their molecular weights were determined from ${ }^{1} \mathrm{H}$ NMR by comparing the integrations of the norbornenyl olefin $(\delta \sim 6 \mathrm{ppm})$ and polymer chain signals $(\delta 5.13-5.18 \mathrm{ppm}$ for PLLA and $\delta 6.32-7.00 \mathrm{ppm}$ for PS) (Table 1). For NB-PS, the calculated molecular weight was in good agreement with the one determined by SEC in THF using PS standards while an overestimated NB-PLLA molecular weight was observed by SEC.

MALDI-TOF MS analysis provides further verification of successful terminal functionalization with norbornene-derivatives. Figures S3 and S4 display MALDI-TOF spectra of NB-PLLA and NB-PS MMs. The peaks are separated by 72 and 104 mass units, corresponding to the molecular weights of a half of the lactide monomer and the styrene monomer, 
respectively. We also compared measured mass values with simulated theoretical mass values (DP = 9 for NB-PLLA and 15 for PS), confirming norbornene-terminated MMs (Figures S3b and S4b).

\subsection{Sequential ROMP of Macromonomers}

PLLA- $b$-PS BBCPs with various PLLA volume fractions $\left(f_{\text {PLLA }}\right)$ were synthesized by adjusting the feed ratio of PS to PLLA. Similar sized PLLA and PS MMs $\left(\mathrm{M}_{\mathrm{n}} \sim 3.0 \mathrm{kDa}\right)$ were used to obtain equivalent radius of effective monomer units, $r_{0}$, for densely grafted bottlebrush architecture (i.e., $\left(\frac{r_{0, P L A A}}{r_{0, P S}}\right)^{1 / 2} \simeq 1$ ) [15]. BBCPs with relatively narrow molecular weight distributions $(\mathrm{D}=1.14-1.28)$ were obtained through sequential $\mathrm{ROMP}$ in $\mathrm{CH}_{2} \mathrm{Cl}_{2}$ using NB-PLLA as the first MM in the presence of Grubbs third-generation catalyst. The molecular characteristics of BBCPs are summarized in Table 2, and their SEC traces are shown in Figure 1. Unreacted MMs were successfully removed from the final product by precipitating the crude polymer solution in hexane and washing with acetonitrile, but lower molecular weight species $\left(\mathrm{M}_{\mathrm{n}} \sim 6 \mathrm{kDa}\right.$, shoulder and tailing in SEC traces) were hard to remove. The small amount of these impurities (less than 10\%) is expected not to affect the self-assembly of BBCPs [23]. The successful sequential ROMP of these two MMs was further confirmed by ${ }^{1} \mathrm{H}$ NMR spectroscopy (Figure S5): the norbornenyl alkene protons of MMs around $\delta 6 \mathrm{ppm}$ disappeared, and the alkene protons of poly(norbornene) backbone appeared around $\delta 5 \mathrm{ppm}$. The volume ratio of PLLA to PS blocks was calculated by comparing the integrals of characteristic signals of PLLA and PS side chains using tabulated density values, 1.25 and $1.04 \mathrm{~g} / \mathrm{cm}^{3}$ for PLLA and PS, respectively [11]. The molecular weights of BBCPs were obtained using SEC with the universal calibration technique by measuring the intrinsic viscosity in order to determine accurate molecular weights regardless of the standards employed in the calibration [33]. The obtained molecular weights are in good agreement with the calculated values.

Table 2. Characteristics of PLLA-b-PS BBCPs synthesized and studied in this work.

\begin{tabular}{|c|c|c|c|c|c|c|c|c|c|}
\hline & $\mathbf{M M}_{1}{ }^{\mathrm{a}}$ & $\mathrm{MM}_{2}{ }^{\mathrm{a}}$ & $\begin{array}{l}{\left[\mathrm{MM}_{1} / \mathrm{C}\right]:} \\
{\left[\mathrm{MM}_{2} / \mathrm{C}\right]}\end{array}$ & $\begin{array}{c}M_{n} \\
\text { (kDa) }^{\mathrm{b}}\end{array}$ & $\bigoplus^{\mathbf{a}}$ & $f_{\text {PLLA }}{ }^{\mathrm{c}}$ & $\begin{array}{l}\text { Domain Size } \\
(\mathrm{nm})^{d}\end{array}$ & $\begin{array}{l}\text { Period } \\
(\mathrm{nm})^{d}\end{array}$ & Morphology ${ }^{d}$ \\
\hline P1 & PLLA $_{3.68 k}$ & $\mathrm{PS}_{3.28 \mathrm{k}}$ & $30: 75$ & 301 & 1.25 & 0.28 & 46 & 72 & $\mathrm{PSC}_{\perp}$ \\
\hline P2 & PLLA $_{3.68 \mathrm{k}}$ & $\mathrm{PS}_{3.28 \mathrm{k}}$ & $30: 60$ & 275 & 1.28 & 0.37 & 51 & 92 & $\mathrm{PS} \mathrm{C}_{\|}$ \\
\hline P3 & PLLA $_{2.56 \mathrm{k}}$ & $\mathrm{PS}_{3.28 \mathrm{k}}$ & $30: 30$ & 171 & 1.20 & 0.47 & 58 & 102 & $\mathrm{~L}_{\perp}$ \\
\hline P4 & PLLA $_{3.68 \mathrm{k}}$ & $\mathrm{PS}_{3.28 \mathrm{k}}$ & $30: 15$ & 220 & 1.14 & 0.75 & - & 70 & PLLA $_{\perp} C_{\perp}$ \\
\hline
\end{tabular}

${ }^{a}$ Determined by SEC in THF using refractive index detector with PS standards. ${ }^{b}$ Determined by SEC in THF using the universal calibration technique. ${ }^{c}$ Calculated by comparing integrations of PS and PLLA proton signals from ${ }^{1} \mathrm{H}$ NMR spectra in $\mathrm{CD}_{2} \mathrm{Cl}_{2} \cdot{ }^{\mathrm{d}}$ Determined by AFM image analysis $\left(C_{\perp}\right.$ : perpendicular cylinders; $C_{\|}$: parallel cylinders; $\mathrm{L}_{\perp}$ : perpendicular lamellae).
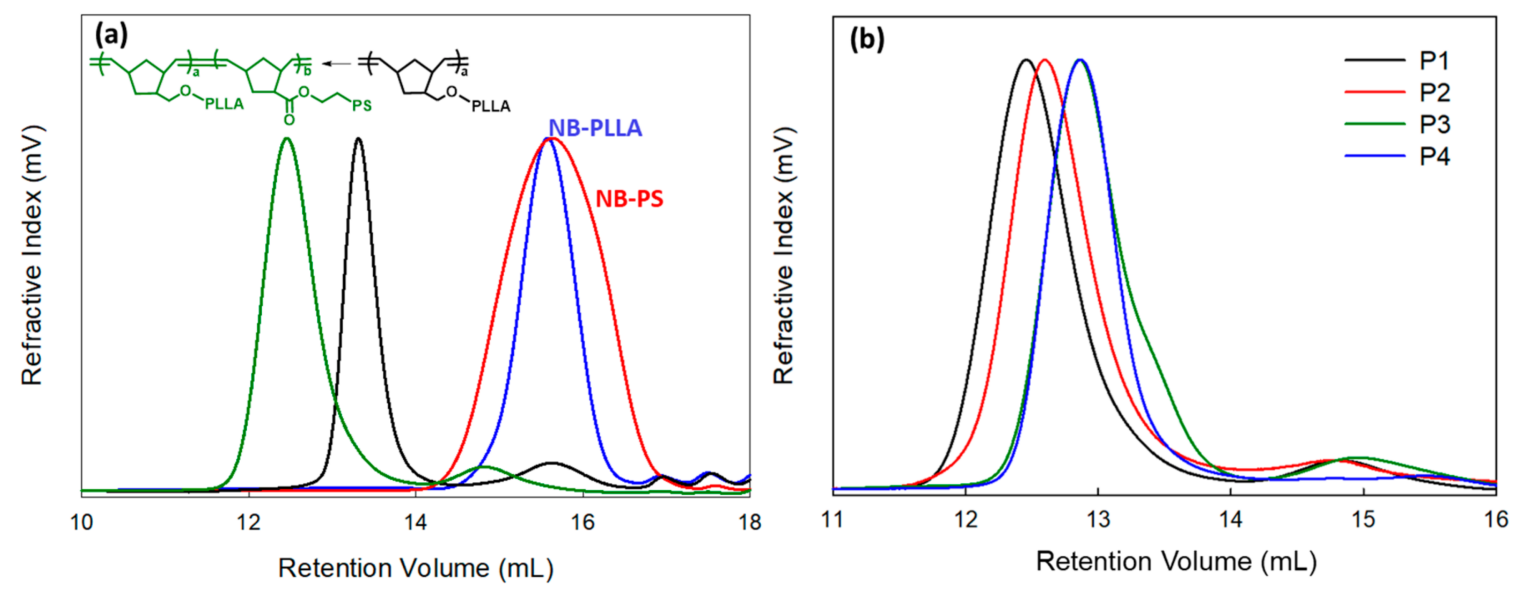

Figure 1. SEC traces: (a) NB-PLLA $3.68 \mathrm{k}$ (blue trace), NB-PS $3.28 \mathrm{k}$ (red trace), the first block brush homopolymer (black trace), and the final BBCP (P1) (green trace) and (b) BBCPs with various PLLA volume fractions. 
The thermal properties of BBCPs were examined by TGA and DSC. As shown in Figure S6 for P3 $\left(f_{\text {PLLA }}=0.47\right)$, a characteristic TGA curve exhibits two distinct stages of weight loss: $200-300{ }^{\circ} \mathrm{C}$ for PLLA and $350-450{ }^{\circ} \mathrm{C}$ for PS. The DSC analysis of BBCPs was performed after erasing the thermal history at $180{ }^{\circ} \mathrm{C}$ during $120 \mathrm{~s}$ under the flow of nitrogen gas at $10^{\circ} \mathrm{C} / \mathrm{min}$. In the DSC second heating scans (Figure S7a), the glass transition temperatures $\left(\mathrm{T}_{\mathrm{g}}\right)$ of PLLA $\left(\mathrm{T}_{\mathrm{g}} \approx 60{ }^{\circ} \mathrm{C}\right)$ and $\mathrm{PS}\left(\mathrm{T}_{\mathrm{g}} \approx 90{ }^{\circ} \mathrm{C}\right)$ were observed from all polymers. However, no hint of PLLA crystallites melting could be observed on the various DSC traces, supporting a poor crystalline arrangement. Interestingly, no recrystallization events were observed for all BBCPs during the subsequent cooling scans, indicating that the crystallization of the PLLA blocks was strongly inhibited (Figure S7b), presumably from the competitive segregation process between the PLLA and PS domains. Besides, the two distinct glass transition events could still be observed for all BBCPs, confirming the phase separation between PLLA and PS domains.

\subsection{Thin Film Self-Assembly of BBCPS}

The selection of solvents for deposition and solvent vapor annealing (SVA) plays an important role in the final morphology of linear PS- $b$-PLA. Based on previously reported findings on PS- $b$-PLA BCPs [34-39], we selected chlorobenzene, as deposition solvent for our studies. Chlorobenzene is defined as PS selective solvents $\left(\chi_{\text {PS-solvent }}<0.5\right)$ based on Hildebrand calculations and the low vapor pressure of chlorobenzene have been shown to drive the formation of well-defined microstructures due to its low evaporation rate during the spin coating process $[39,40]$. PLLA- $b$-PS BBCPs thin-films (30-50 $\mathrm{nm}$ in thickness) were deposited from chlorobenzene solution on Si substrates by spin-coating.

Interestingly, as-cast thin films of PLLA- $b$-PS BBCPs already exhibit self-assembled defective patterns as shown in Figure $2 \mathrm{a}, \mathrm{d}$. In order to improve the quality of thin-film morphologies, spin-coating was carried out on heated Si substrates. In fact, it has been demonstrated that spin coating at the temperature above $\mathrm{T}_{\mathrm{g}}$ of one block and below $\mathrm{T}_{\mathrm{g}}$ of another block reduce substrate influences on microphase separation of linear BCPs [39]. Prior to spin-coating of PLLA- $b$-PS BBCPs, Si substrates were thus heated at $\sim 75^{\circ} \mathrm{C}$ (slightly above $\mathrm{T}_{\mathrm{g}}$ of PLLA and below $\mathrm{T}_{\mathrm{g}}$ of PS) for $5 \mathrm{~min}$. We observed that spin-coating on heated Si substrates provided a way to promote ordering and well-defined patterns as shown in Figure $2 b$,e, respectively. The surface topographies of both PLLA perpendicular cylinders and lamellae are more distinct in comparison to Figure $2 \mathrm{a}, \mathrm{d}$. We believe that the escalated substrate temperature increases the evaporation rate of the solvent, thereby driving phase segregation. Moreover, we cannot discard the possibility that the overall mobility of the system was increased due to the elevated substrate temperature. We observed similar behavior after heating substrates at $100{ }^{\circ} \mathrm{C}$ (data not shown). However, higher substrate temperature treatment, e.g., $>125^{\circ} \mathrm{C}$, resulted in dewetted films.

In order to further enhance pattern definition, we treated as-cast heated films with SVA. The segregation between PS and PLA is affected by solvent uptake, and an effective interaction parameter $\left(\chi_{\text {eff }}\right)$ can be defined to relate the influence of the solvent: $\chi_{\text {eff }}=\chi(1$ $\left.-\Phi_{\mathrm{S}}\right)$, where $\chi_{\mathrm{eff}}$ and $\chi$ are the Flory-Huggins interaction parameters in the presence and absence of the solvent respectively, and $\Phi_{\mathrm{S}}$ is the volume fraction of solvent [37]. While the solvent uptake by the PLLA- $b$-PS BBCP films reduces the overall $\chi$, solvent molecules permeating through the films also decrease the $T_{g}$ values of both blocks. SVA treatment under chloroform vapors for as short as $5 \mathrm{~min}$ resulted in enhanced long-range order of both morphologies (Figure 2c,f). P1 exhibits a dot pattern possessing a period of $72 \mathrm{~nm}$ with domain sizes of $46 \mathrm{~nm}$, while P3 shows a line pattern having period of $102 \mathrm{~nm}$ with domain sizes of $58 \mathrm{~nm}$. The obtained period sizes are well beyond those typically accessible by linear BCPs, and achieved in a short period of time. We also investigated the selfassembly of PLLA-rich BBCP $\left(\mathrm{P} 4, f_{\mathrm{PLLA}}=0.75\right)$ (Figure 59$)$. Owing to the drastic change in $f_{\text {PLLA }}$, well-defined patterns were not observed from as-cast or as-cast heated films of P4. However, partial dot features with large variation in domain size were observed after $5 \mathrm{~min}$ SVA, showing PS domains within the major component PLLA matrix. In summary, with 
the increase of the PLLA volume fraction, morphological transitions from PLLA cylinders to lamellae to PS cylinders were observed in accordance with the theoretical phase diagram, recently reported by Zhulina et al. [15].
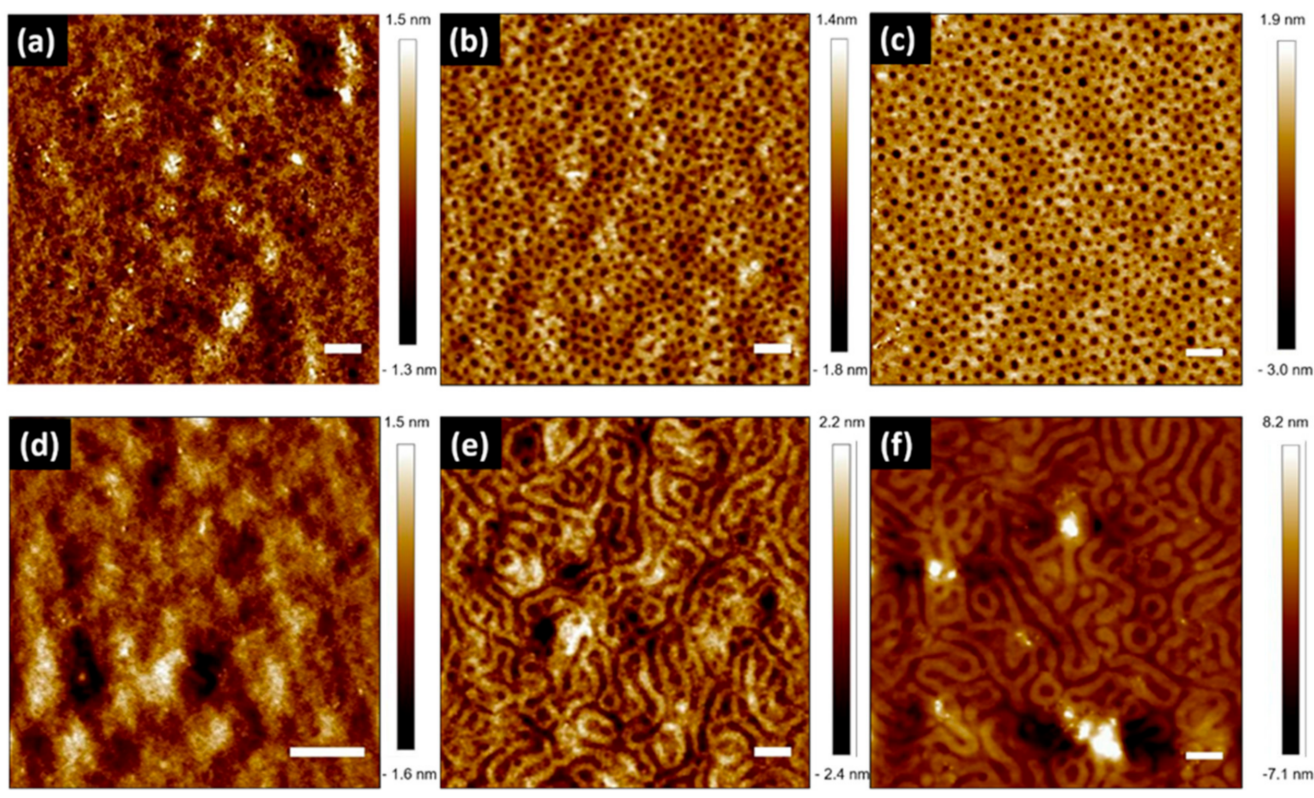

Figure 2. AFM height images of $\mathbf{P 1}(\mathbf{a}-\mathbf{c})$ and $\mathbf{P 3}(\mathbf{d}-\mathbf{f})$ spin-cast from chlorobenzene solution onto Si substrate. (a,d) as-cast with spin-coating at room temperature; $(\mathbf{b}, \mathbf{e})$ as-cast with spin-coating on heated Si substrate; (c,f) annealed in chloroform vapor for $5 \mathrm{~min}$ after spin-coating on heated Si substrate. Scale bars are $200 \mathrm{~nm}$.

\subsection{Solvent Effects on PLLA-b-PS BBCP Thin Film Self-Assembly}

Next, we discuss the polymer-solubility consideration for a cylindrical PLLA- $b$-PS $\mathrm{BBCP}$ and the ability to change cylinder orientation depending on SVA conditions. While P1 $\left(f_{\text {PLLA }}=0.28\right)$ and P3 $\left(f_{\text {PLLA }}=0.47\right)$ formed cylindrical and lamellar patterns by spin-casting using chlorobenzene, we observed cloudy, highly viscous solutions from P2 $\left(f_{\text {PLLA }}=0.37\right)$ solution in chlorobenzene, and spin-cast P2 films from chlorobenzene solution on either non-heated or heated substrates did not exhibit a clear microphase separation (Figure S8). In order to rectify this, we used THF as a casting solvent for P2 and a clear solution was readily formed, inferring PLLA and PS miscibility. As shown in Figure 3, P2 shows the ability to orient domain features through either SVA in THF for perpendicular orientation or SVA in chloroform for parallel orientation. This can be explained by the choice of selective solvents and their subsequent effect on the polymer/air interface. Empirical studies have shown that a neutral solvent like THF produces perpendicularly orientated PLA cylinders $[30,35]$. In contrast, a selective solvent like chloroform orients cylinders parallel to form line-space patterns [41]. Overall, the PLLA- $b$-PS BBCPs developed here show that it is possible to pattern large periodic dot and line features in a rapid timeframe. Moreover, we have demonstrated that the orientation of PLLA cylinders can be controlled to produce perpendicular or parallel features based on the choice of SVA solvent. 

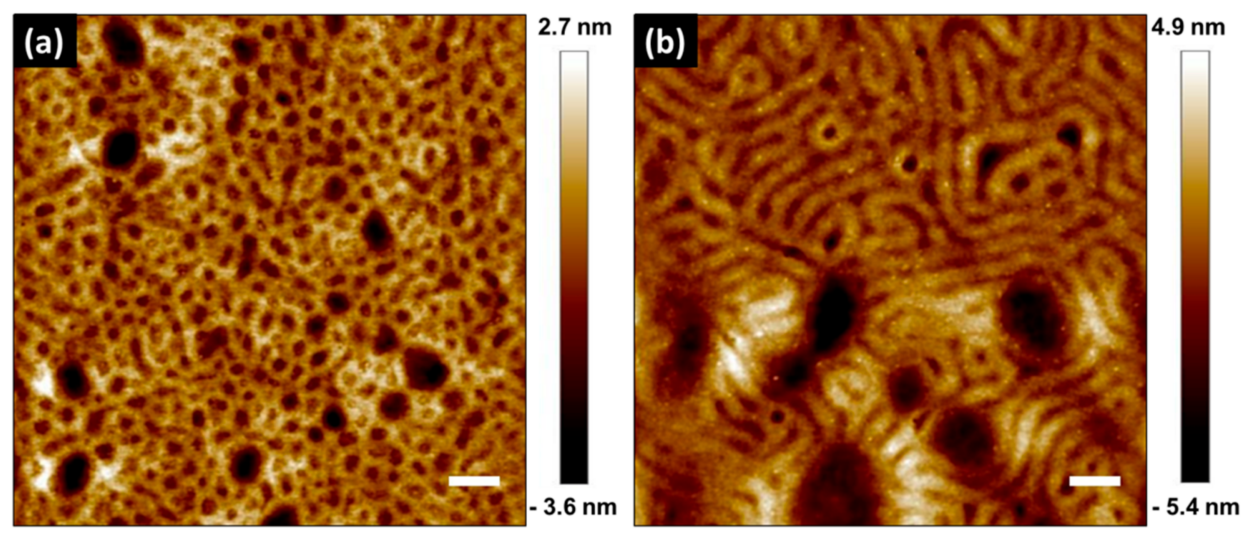

Figure 3. AFM height images of $\mathbf{P} 2$ after spin-coating from THF solution on heated Si substrate followed by solvent vapor annealing in (a) THF and (b) chloroform for $5 \mathrm{~min}$. Scale bars are $200 \mathrm{~nm}$.

\subsection{Generation of Nanoporous Thin-Films}

BBCPs containing PLA are highly attractive materials for the fabrication of nonporous materials because of the degradable ester group which can be hydrolytically decomposed. The dry etching of PLA has been known to produce a good-quality pattern over a large area compared to wet etch methods [42]. Thus, we used oxygen plasma treatment to selectively remove the PLLA domains, which are etched faster than the PS domains under $\mathrm{O}_{2}$ chemistry due to the susceptibility of the PLA ester linkages [43,44]. Figure $4 a, b$ displays top-down SEM images of PLLA- $b$-PS BBCPs films after a brief oxygen plasma treatment, revealing well-defined dot and line-space patterns. The obtained porous PS film template are ideal to be used for pore-filling with a variety of ingredients such as metals or dielectrics for membranes, photonics, and catalysis applications [45-47].
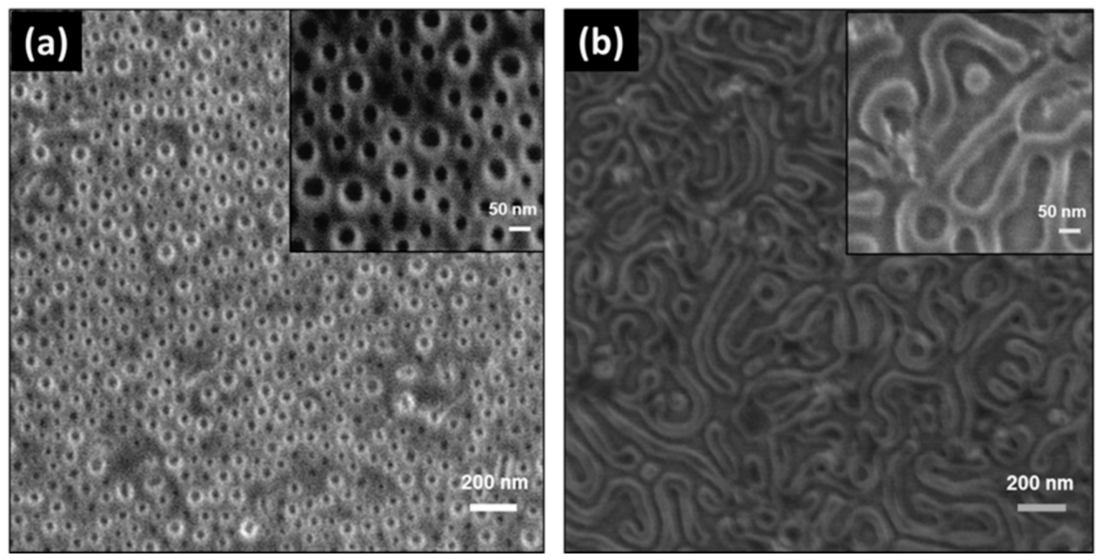

Figure 4. Top-down SEM images of P1 (a) and P 3 (b) after oxygen plasma etching.

\section{Conclusions}

In summary, we prepared a series of well-defined PLLA-b-PS BBCPs, and investigated their morphologies as a function of the relative block volume factions. Interestingly, BBCPs containing similar sized side chains self-assembled rapidly into ordered cylindrical or lamellar structures. By simply varying $f_{\text {PLLA }}$ from 0.27 to 0.75 , morphological transitions occurred (cylinder-lamellae-cylinder). For P1 and P3, cylindrical and lamellar morphologies were observed right after spin-coating, and P2 showed the change in orientation of cylindrical domains depending on the type of solvent for SVA for $5 \mathrm{~min}$. We initially expected the PLLA crystallinity to enrich the self-assembly behavior of PLLA- $b$-PS BBCPs, possibly leading to the volume fraction dependent morphology transitions like linear BCPs. Further studies to leverage the crystallinity of PLLA as an additional tool to tune BBCP selfassembly are required in the future to fully comprehend the mechanism in these systems. 
Additionally, PLLA- $b$-PS BBCPs films were used to prepare nonporous templates by oxygen plasma etching. We believe that the facile synthesis of PLLA-PS BBCP disclosed here contribute to a better understanding of the relationship between $\mathrm{BBCP}$ architecture and the enhanced self-assembly behavior in thin film form. The findings progress our knowledge on the growing interest of controlling BBCPs in thin-films to produce functional materials.

Supplementary Materials: The following are available online, Experimental section, Figure S1: ${ }^{1} \mathrm{H}$ NMR and ${ }^{13} \mathrm{C}$ NMR Spectra of NB-PLLA, Figure S2: ${ }^{1} \mathrm{H}$ NMR and ${ }^{13} \mathrm{C}$ NMR Spectra of NB-PS, Figure S3: MALDI-TOF MS spectrum of NB-PLLA, Figure S4: MALDI-TOF MS spectrum of NB-PS, Figure S5: $1 \mathrm{H}$ NMR spectra of two MMs and of the resulting BBCP, Figure S6: TGA of P3 under nitrogen atmosphere, Figure S7: DSC thermograms of BBCPs recorded at heating rate of $10^{\circ} \mathrm{C} / \mathrm{min}$ under nitrogen, Figure S8: AFM height images of P2 spin-cast from chlorobenzene solution onto Si substrate, Figure S9: AFM height images of P4 spin-cast from chlorobenzene solution onto Si substrate. Experimental details and additional characterization data $\left({ }^{1} \mathrm{H}\right.$ NMR and ${ }^{13} \mathrm{C}$ NMR spectra, MALDI-TOF spectra, DSC and TGA thermograms, and AFM images).

Author Contributions: Synthesis, investigation and data curation, E.J. and C.C.; data analysis: E.J., C.C. and G.F.; writing-original draft preparation, E.J. and C.C.; writing-review and editing, E.J., C.C. and G.F.; conceptualization and supervision, G.F.; funding acquisition, G.F. All authors have read and agreed to the published version of the manuscript.

Funding: The authors declare no competing financial interest.

Institutional Review Board Statement: Not applicable.

Informed Consent Statement: Not applicable.

Data Availability Statement: The data presented in this study are available on request from the corresponding author.

Acknowledgments: This work was supported by the European H2020 SUN-PILOT project under grant agreement no. 760915. MALDI-TOF analysis was conducted at CESAMO (Bordeaux, France).

Conflicts of Interest: The authors declare no conflict of interest.

Sample Availability: Not available.

\section{References}

1. Xia, Y.; Olsen, B.D.; Kornfield, J.A.; Grubbs, R.H. Efficient synthesis of narrowly dispersed brush copolymers and study of their assemblies: The importance of side chain arrangement. J. Am. Chem. Soc. 2009, 131, 18525-18532. [CrossRef] [PubMed]

2. Miyake, G.M.; Weitekamp, R.A.; Piunova, V.A.; Grubbs, R.H. Synthesis of isocyanate-based brush block copolymers and their rapid self-assembly to infrared-reflecting photonic crystals. J. Am. Chem. Soc. 2012, 134, 14249-14254. [CrossRef]

3. Li, X.; Prukop, S.L.; Biswal, S.L.; Verduzco, R. Surface properties of bottlebrush polymer thin films. Macromolecules 2012, 45, 7118-7127. [CrossRef]

4. Sveinbjörnsson, B.R.; Weitekamp, R.A.; Miyake, G.M.; Xia, Y.; Atwater, H.A.; Grubbs, R.H. Rapid self-assembly of brush block copolymers to photonic crystals. Proc. Natl. Acad. Sci. USA 2012, 109, 14332-14336. [CrossRef]

5. Sun, G.; Cho, S.; Clark, C.; Verkhoturov, S.V.; Eller, M.J.; Li, A.; Pavía-Jiménez, A.; Schweikert, E.A.; Thackeray, J.W.; Trefonas, P.; et al. Nanoscopic cylindrical dual concentric and lengthwise block brush terpolymers as covalent preassembled high-resolution and high-sensitivity negative-tone photoresist materials. J. Am. Chem. Soc. 2013, 135, 4203-4206. [CrossRef]

6. Verduzco, R.; Li, X.; Pesek, S.L.; Stein, G.E. Structure, function, self-assembly, and applications of bottlebrush copolymers. Chem. Soc. Rev. 2015, 44, 2405-2420. [CrossRef] [PubMed]

7. Liberman-Martin, A.L.; Chu, C.K.; Grubbs, R.H. Application of Bottlebrush Block Copolymers as Photonic Crystals. Macromol. Rapid Commun. 2017, 38, 1700058. [CrossRef] [PubMed]

8. Nguyen, H.V.T.; Detappe, A.; Harvey, P.; Gallagher, N.; Mathieu, C.; Agius, M.P.; Zavidij, O.; Wang, W.; Jiang, Y.; Rajca, A.; et al. Pro-organic radical contrast agents ("pro-ORCAs") for real-time MRI of pro-drug activation in biological systems. Polym. Chem. 2020, 11, 4768-4779. [CrossRef]

9. Vohidov, F.; Milling, L.E.; Chen, Q.; Zhang, W.; Bhagchandani, S.; Nguyen, H.V.-T.; Irvine, D.J.; Johnson, J.A. ABC triblock bottlebrush copolymer-based injectable hydrogels: Design, synthesis, and application to expanding the therapeutic index of cancer immunochemotherapy. Chem. Sci. 2020, 11, 5974-5986. [CrossRef]

10. Jiang, Z.; Liu, H.; He, H.; Ribbe, A.E.; Thayumanavan, S. Blended Assemblies of Amphiphilic Random and Block Copolymers for Tunable Encapsulation and Release of Hydrophobic Guest Molecules. Macromolecules 2020, 53, 2713-2723. [CrossRef] 
11. Rzayev, J. Synthesis of polystyrene-polylactide bottlebrush block copolymers and their melt self-assembly into large domain nanostructures. Macromolecules 2009, 42, 2135-2141. [CrossRef]

12. Nikovia, C.; Theodoridis, L.; Alexandris, S.; Bilalis, P.; Hadjichristidis, N.; Floudas, G.; Pitsikalis, M. Macromolecular Brushes by Combination of Ring-Opening and Ring-Opening Metathesis Polymerization. Synthesis, Self-Assembly, Thermodynamics, and Dynamics. Macromolecules 2018, 51, 8940-8955. [CrossRef]

13. Rajaram, S.; Choi, T.L.; Rolandi, M.; Fréchet, J.M.J. Synthesis of dendronized diblock copolymers via ring-opening metathesis polymerization and their visualization using atomic force microscopy. J. Am. Chem. Soc. 2007, 129, 9619-9621. [CrossRef] [PubMed]

14. Xia, Y.; Kornfield, J.A.; Grubbs, R.H. Efficient synthesis of narrowly dispersed brush polymers via living ring-opening metathesis polymerization of macromonomers. Macromolecules 2009, 42, 3761-3766. [CrossRef]

15. Zhulina, E.B.; Sheiko, S.S.; Dobrynin, A.V.; Borisov, O.V. Microphase Segregation in the Melts of Bottlebrush Block Copolymers. Macromolecules 2020, 53, 2582-2593. [CrossRef]

16. Runge, M.B.; Bowden, N.B. Synthesis of high molecular weight comb block copolymers and their assembly into ordered morphologies in the solid state. J. Am. Chem. Soc. 2007, 129, 10551-10560. [CrossRef] [PubMed]

17. Brett Runge, M.; Lipscomb, C.E.; Ditzler, L.R.; Mahanthappa, M.K.; Tivanski, A.V.; Bowden, N.B. Investigation of the assembly of comb block copolymers in the solid state. Macromolecules 2008, 41, 7687-7694. [CrossRef]

18. Gu, W.; Huh, J.; Hong, S.W.; Sveinbjornsson, B.R.; Park, C.; Grubbs, R.H.; Russell, T.P. Self-assembly of symmetric brush diblock copolymers. ACS Nano. 2013, 7, 2551-2558. [CrossRef]

19. Hong, S.W.; Gu, W.; Huh, J.; Sveinbjornsson, B.R.; Jeong, G.; Grubbs, R.H.; Russell, T.P. On the self-assembly of brush block copolymers in thin films. ACS Nano. 2013, 7, 9684-9692. [CrossRef]

20. Dalsin, S.J.; Rions-Maehren, T.G.; Beam, M.D.; Bates, F.S.; Hillmyer, M.A.; Matsen, M.W. Bottlebrush Block Polymers: Quantitative Theory and Experiments. ACS Nano. 2015, 9, 12233-12245. [CrossRef]

21. Kim, M.J.; Yu, Y.G.; Chae, C.G.; Seo, H.B.; Bak, I.G.; Mallela, Y.L.N.K.; Lee, J.S. w-Norbornenyl Macromonomers: In Situ Synthesis by End-Capping of Living Anionic Polymers Using a Norbornenyl-Functionalized $\alpha$-Phenyl Acrylate and Their Ring-Opening Metathesis Polymerization. Macromolecules 2019, 52, 103-112. [CrossRef]

22. Jiang, L.; Nykypanchuk, D.; Ribbe, A.E.; Rzayev, J. One-Shot Synthesis and Melt Self-Assembly of Bottlebrush Copolymers with a Gradient Compositional Profile. ACS Macro. Lett. 2018, 619-623. [CrossRef]

23. Gai, Y.; Song, D.P.; Yavitt, B.M.; Watkins, J.J. Polystyrene-block-poly(ethylene oxide) Bottlebrush Block Copolymer Morphology Transitions: Influence of Side Chain Length and Volume Fraction. Macromolecules 2017, 50, 1503-1511. [CrossRef]

24. Cho, S.; Son, J.; Kim, I.; Ahn, H.; Jang, H.S.; Joo, S.H.; Park, K.H.; Lee, E.; Kim, Y.; Ahn, S.K. Asymmetric polystyrene-polylactide bottlebrush random copolymers: Synthesis, self-assembly and nanoporous structures. Polymer 2019, 175, 49-56. [CrossRef]

25. Sunday, D.F.; Dolejsi, M.; Chang, A.B.; Richter, L.J.; Li, R.; Kline, R.J.; Nealey, P.F.; Grubbs, R.H. Confinement and Processing Can Alter the Morphology and Periodicity of Bottlebrush Block Copolymers in Thin Films. ACS Nano. 2020, 14, 17476-17486. [CrossRef] [PubMed]

26. Ho, R.M.; Chiang, Y.W.; Tsai, C.C.; Lin, C.C.; Ko, B.T.; Huang, B.H. Three-Dimensionally Packed Nanohelical Phase in Chiral Block Copolymers. J. Am. Chem. Soc. 2004, 126, 2704-2705. [CrossRef] [PubMed]

27. Ho, R.M.; Chen, C.K.; Chiang, Y.W.; Ko, B.T.; Lin, C.C. Tubular nanostructures from degradable core-shell cylinder microstructures in chiral diblock copolymers. Adv. Mater. 2006, 18, 2355-2358. [CrossRef]

28. Ho, R.M.; Chen, C.K.; Chiang, Y.W. Novel nanostructures from self-assembly of chiral block copolymers. Macromol. Rapid. Commun. 2009, 30, 1439-1456. [CrossRef] [PubMed]

29. Jackson, E.A.; Hillmyer, M.A. Nanoporous membranes derived from block copolymers: From drug delivery to water filtration. ACS Nano. 2010, 4, 3548-3553. [CrossRef] [PubMed]

30. Vayer, M.; Hillmyer, M.A.; Dirany, M.; Thevenin, G.; Erre, R.; Sinturel, C. Perpendicular orientation of cylindrical domains upon solvent annealing thin films of polystyrene-b-polylactide. Thin. Solid. Films. 2010, 518, 3710-3715. [CrossRef]

31. Theodosopoulos, G.V.; Bitsi, S.L.; Pitsikalis, M. Complex Brush-Like Macromolecular Architectures via Anionic and Ring Opening Metathesis Polymerization: Synthesis, Characterization, and Thermal Properties. Macromol. Chem. Phys. 2018, 219 , 1700253. [CrossRef]

32. Rule, J.D.; Moore, J.S. ROMP reactivity of endo- and exo-dicyclopentadiene. Macromolecules 2002, 35, 7878-7882. [CrossRef]

33. Grubisic, Z.; Rempp, P.; Benoit, H. A universal calibration for gel permeation chromatography. J. Polym. Sci. Part. B. Polym. Lett. 1967, 5, 753-759. [CrossRef]

34. Olayo-Valles, R.; Guo, S.; Lund, M.S.; Leighton, C.; Hillmyer, M.A. Perpendicular Domain Orientation in Thin Films of Polystyrene-Polylactide Diblock Copolymers. Macromolecules 2005, 38, 10101-10108. [CrossRef]

35. Baruth, A.; Seo, M.; Lin, C.H.; Walster, K.; Shankar, A.; Hillmyer, M.A.; Leighton, C. Optimization of long-range order in solvent vapor annealed poly(styrene)-block-poly(lactide) thin films for nanolithography. ACS Appl. Mater. Interfaces 2014, 6, 13770-13781. [CrossRef]

36. Sinturel, C.; Grosso, D.; Boudot, M.; Amenitsch, H.; Hillmyer, M.A.; Pineau, A.; Vayer, M. Structural transitions in asymmetric poly(styrene)-block -poly(lactide) thin films induced by solvent vapor exposure. ACS Appl. Mater. Interfaces 2014, 6, 12146-12152. [CrossRef] 
37. Cummins, C.; Mokarian-Tabari, P.; Andreazza, P.; Sinturel, C.; Morris, M.A. Solvothermal Vapor Annealing of Lamellar Poly(styrene)-block-poly(d,l-lactide) Block Copolymer Thin Films for Directed Self-Assembly Application. ACS Appl. Mater. Interfaces 2016, 8, 8295-8304. [CrossRef]

38. She, M.S.; Lo, T.Y.; Hsueh, H.Y.; Ho, R.M. Nanostructured thin films of degradable block copolymers and their applications. NPG Asia Mater. 2013, 5, 42. [CrossRef]

39. Ho, R.M.; Tseng, W.H.; Fan, H.W.; Chiang, Y.W.; Lin, C.C.; Ko, B.T.; Huang, B.H. Solvent-induced microdomain orientation in polystyrene-b-poly(l-lactide) diblock copolymer thin films for nanopatterning. Polymer 2005, 46, 9362-9377. [CrossRef]

40. Auras, R.; Harte, B.; Selke, S. An overview of polylactides as packaging materials. Macromol. Biosci. 2004, 4, 835-864. [CrossRef] [PubMed]

41. Gowd, E.B.; Böhme, M.; Stamm, M. In Situ GISAXS Study on Solvent Vapour Induced Orientation Switching in PS- b -P4VP Block Copolymer Thin Films. IOP Conf. Ser. Mater. Sci. Eng. 2010, 14, 012015. [CrossRef]

42. Cummins, C.; Mokarian-Tabari, P.; Holmes, J.D.; Morris, M.A. Selective etching of polylactic acid in poly(styrene)-block-poly(d,l) lactide diblock copolymer for nanoscale patterning. J. Appl. Polym. Sci. 2014, 131, 9493-9504. [CrossRef]

43. Keen, I.; Yu, A.; Cheng, H.-H.; Jack, K.S.; Nicholson, T.M.; Whittaker, A.K.; Blakey, I. Control of the orientation of symmetric poly (styrene)-block-poly (D, L-lactide) block copolymers using statistical copolymers of dissimilar composition. Langmuir 2012, 28, 15876-15888. [CrossRef] [PubMed]

44. Keen, I.; Cheng, H.-H.; Yu, A.; Jack, K.S.; Younkin, T.R.; Leeson, M.J.; Whittaker, A.K.; Blakey, I. Behavior of Lamellar Forming Block Copolymers under Nanoconfinement: Implications for Topography Directed Self-Assembly of Sub-10 nm Structures. Macromolecules 2014, 47, 276-283. [CrossRef]

45. Stefik, M.; Guldin, S.; Vignolini, S.; Wiesner, U.; Steiner, U. Block copolymer self-assembly for nanophotonics. Chem. Soc. Rev. 2015, 44, 5076-5091. [CrossRef]

46. Cummins, C.; Lundy, R.; Walsh, J.J.; Ponsinet, V.; Fleury, G.; Morris, M.A. Enabling future nanomanufacturing through block copolymer self-assembly: A review. Nano. Today 2020, 35, 100936. [CrossRef]

47. Zhou, J.; Wang, Y. Selective Swelling of Block Copolymers: An Upscalable Greener Process to Ultrafiltration Membranes? Macromolecules 2020, 53, 5-17. [CrossRef] 